\title{
RANTES and Chemotactic Activity in Synovial Fluids From Patients With Rheumatoid Arthritis and Osteoarthritis
}

\author{
Joanna Stanczyk, ${ }^{1}$ Marek L. Kowalski, ${ }^{1}$ Janina Grzegorczyk, ${ }^{1}$ Barbara Szkudlinska, ${ }^{1}$ \\ Marzanna Jarzebska, ${ }^{1}$ Marek Marciniak, ${ }^{2}$ and Marek Synder ${ }^{2}$ \\ ${ }^{1}$ Department of Clinical Immunology and Allergy, Medical University of Lodz, 92216 Lodz, Poland \\ ${ }^{2}$ Department of Orthopaedics and Traumatology, Medical University of Lodz, 91002 Lodz, Poland
}

Received 25 July 2005; accepted 1 September 2005

\begin{abstract}
A massive accumulation of inflammatory cells in synovial tissues is a major pathological feature of rheumatoid arthritis (RA). Neutrophiles dominate synovial fluid while rheumatoid synovium is infiltrated with mononuclear cells. Mechanisms regulating influx of particular subpopulations of leukocytes into articular cavity and synovium compartment are not completely defined. An increasing amount of data supports a crucial role of a C-C chemokine RANTES in the RA pathogenesis. Our objective is to evaluate chemotactic activity for neutrophils (NCA), lymphocytes (LCA), and monocytes (MoCA) in SFs obtained from patients with RA and osteoarthritis (OA). We also aimed to characterise the relation between chemotactic activity, RANTES, and percentage distribution of leukocytes in SF. SFs from 11 patients with RA and 6 with OA were included in the study. Modified microchamber Boyden method was employed to assess chemotactic activity. Cytological and biochemical analysis of SF was performed. RANTES was measured with ELISA. Rheumatoid SFs were rich in cells with predominance of neutrophiles while osteoarthritic fluids were lymphocytic. RA SFs were also characterised by increased lactoferrin level. Both NCA and LCA were higher in SF from patients with RA (62 \pm 12 and $24 \pm 6$ cells/HPF, resp) as compared to patients with OA $(23 \pm 6 ; P<.05$ and $6 \pm 2$ cells/HPF; $P<0.05)$. The chemoattractive effect of RA SF was more pronounced on neutrophiles than on lymphocytes. RA SF expressed high RANTES levels $(145 \pm 36 \mathrm{pg} / \mathrm{mL})$, while OA SF was characterised by only trace amount of this chemokine $(2 \pm 1 \mathrm{pg} / \mathrm{mL})$. We found positive correlation of RANTES with chemotactic activity for mononuclear cells (LCA + MoCA; $R=0.61 ; P<.05$ ). Surprisingly, RANTES correlated also positively with neutrophiles number $(R=0.77 ; P<0.001)$. Rheumatoid SF possesses strong chemotactic potency for leukocytes. RANTES is overexpressed in RA SF and is a potential mediator influencing intensity and composition of cellular infiltration in joints affected with inflammatory arthritis.
\end{abstract}

\section{INTRODUCTION}

The synovial fluid (SF) in rheumatoid arthritis (RA) is characterised by increased cellularity with predominance of neutrophils. Also in the rheumatoid synovium besides typical synovial hyperplasia a massive inflammatory infiltration consisting of mononuclear cells (MNC) has been observed. Cells accumulating in rheumatoid tissues produce a number of mediators including cytokines and prostanoids, which play a crucial role in the progression of inflammation and tissue damage [1]. Neutrophils present in SF release proteolytic enzymes (eg, metalloproteinases) participating in destruction of the articular cartilage [2].

Correspondence and reprint requests to Joanna Stanczyk, Department of Clinical Immunology and Allergy, Medical University of Lodz, 92216 Lodz, Poland; joannast@csk.umed.lodz.pl
Mechanisms responsible for accumulation of leukocytes in rheumatoid joints have not been fully understood. Migration of leukocytes into the extravascular space is the main stage in the development of cellular infiltration. This phenomenon depends on both the expression of adhesion molecules on the endothelial cells and the gradient of chemotactic factors produced at the site of inflammation. Among various chemotactic factors (weakly characterised) chemokines constitute a group of important mediators, and the major role of RANTES (regulated upon activation, normal $\mathrm{T}$ cell expressed and secreted), a C-C family derived chemokine, in RA has been established. SFs obtained from patients with RA show high RANTES level, and high serum concentration of RANTES has been associated with a rapid progression of radiographic changes [3]. The percentage of lymphocytes and monocytes with the CCR5 receptor expression (with RANTES as a main ligand) in the rheumatoid SF many times exceeds the value observed in the peripheral blood $[4,5]$. 
The aim of this study was to evaluate chemotactic activity for attracting neutrophils, lymphocytes, and monocytes in SF obtained from patients with RA and osteoarthritis (OA). We also aimed to characterise the relation between chemotactic activity and RANTES in SF studied and for the first time we simultaneously related them to percentage distribution of cells in SF.

\section{METHODS}

\section{Patients}

SFs were obtained from 11 subjects with RA ( 9 females with mean age of $57 \pm 9$ years and 2 males with mean age of $55 \pm 6$ years) and 6 subjects with OA (females with mean age of $65 \pm 5$ years). Approval of the local ethics committee was obtained prior to the study. All patients with RA fulfilled the 1987 American Rheumatism Association criteria [6].

\section{Synovial fluids}

SF obtained during therapeutic arthrocentesis was transferred to heparinised tubes, transported immediately to laboratory, and centrifuged. Supernatants were immediately frozen at $-70^{\circ} \mathrm{C}$ for biochemical analysis. The cell pellet was resuspended and the leukocytes were counted. Cytospin preparations were performed, stained with MayGrunwald-Giemsa and inspected by light microscopy.

\section{Measurement of chemotactic activity}

Leukocytes were obtained from peripheral blood of a healthy volunteer. Neutrophils were fractionated by Histopaq 1119 (Sigma, USA) and 1077 (Sigma, USA) density gradient centrifugation. Histopaq 1077 density gradient centrifugation was used to obtain MNC. Cells were suspended at $2 \times 10^{6}$ cells $/ \mathrm{mL}$. Viability exceeded $95 \%$ as assessed by trypan blue exclusion test. SFs were tested for chemotactic potency with the Boyden microchamber method on freshly isolated cells $\left(2 \times 10^{6}\right.$ cells $\left./ \mathrm{mL}\right)$. Polycarbonate membranes with pore size of $5 \mu \mathrm{m}$ or $8 \mu \mathrm{m}$ were used for neutrophils or MNC, respectively. After $1.5 \mathrm{~h}$ of incubation at $37^{\circ} \mathrm{C}$ the cells were fixed and stained. The cells that migrated through the membranes were counted microscopically in 5 standardised high-power field (HPF) at 400-fold magnification. Lymphocytes and monocytes were distinguished according to morphological criteria. Results were expressed as the mean cell number calculated from $5 \mathrm{HPF}$.

\section{Immunoassay}

RANTES in SF was measured using a commercial enzyme-linked immunosorbent assay (ELISA) (Endogen, USA) with sensitivity of $2 \mathrm{pg} / \mathrm{mL}$. Briefly, samples were added in duplicate to a 96-well microplate precoated with a polyclonal anti-human RANTES antibody. Following incubation and washing anti-human RANTES biotinlabelled detecting antibody plates were used. In the next stage poly-HRP streptavidin conjugate was added. Chromogen tetramethylbenzidine was used to develop colour reaction. Plates were read at $450 \mathrm{~nm}$ in an ELISA reader Allercoat (Sanofi Pasteur, France).

\section{Biochemical analysis of SF}

Total protein in each sample was measured by Lowry's method. Albumin in SF samples was assayed by noncompetitive ELISA with anti-human serum albumin (HSA; Cappel, USA) and peroxidase-conjugated anti-HSA. Lactoferrin (LF) levels were measured by noncompetitive ELISA by the standard procedure with rabbit anti-human LF conjugated to horseradish peroxidase (Cappel, USA). Absorbancy was measured with microplate reader ELISA LP 400 (Diagnostic Pasteur, France) at 410 and $490 \mathrm{~nm}$.

\section{Statistical analysis}

All data were expressed as mean \pm SEM. Statistical analysis of differences between groups was carried out by Mann Whitney U test. The statistical significance of relationships was tested using Spearman's and Pearson's correlation analysis. A $P$ value $\leq .05$ was considered statistically significant.

\section{Results \\ SF cellular and biochemical analysis}

Synovial fluids from patients with RA were rich in cells with predominating neutrophils, contrary to OA synovial fluids, which contained low number of cells and were mainly lymphocytic (Table 1). In rheumatoid SF, higher concentration of lactoferrin was observed as compared to osteoarthritic SF $(P<.01)$. A positive correlation between the LF concentration in the SF and as well the percentage $(R=0.76 ; P<.05)$ and total number of neutrophils $(R=0.67 ; P<.05)$ was found. Simultaneously we noted a negative correlation between LF and the percentage of lymphocytes $(R=-0.72 ; P<.05)$. The mean total protein and albumin concentration in SF from both groups studied did not differ.

\section{SF chemotactic activity}

RA and OA synovial fluids contained chemotactic activity for neutrophils (NCA). However, the mean number of cells attracted by fluids from RA patients was higher $(62 \pm 12$ cells/HPF; $18-115)$ than that attracted by fluids from OA patients $(23 \pm 6 ; 2-42 ; P<.05)$ (Figure 1a). NCA in RA SF was $79 \pm 15 \%$ of ZAS chemotactic activity as compared to $29 \pm 8 \%$ of ZAS chemotactic activity in OA group (Figure 2). A positive correlation between NCA and the neutrophil percentage $(R=0.58 ; P<.05)$ and a negative correlation between NCA and the lymphocyte percentage $(R=0.54 ; P<.05)$ were also found.

Rheumatoid SF expressed the chemotactic activity for lymphocytes (LCA) at the mean level of $24 \pm 6$ cells/HPF (3-69 cells/HPF; Figure 1b), which constituted 185 $\pm 46 \%$ of ZAS chemotactic activity. The chemotactic activity for monocytes (MoCA) detected in SF from RA patients (26 \pm 4 cells/HPF, $13-51$ cells/HPF; Figure 1c) constituted 
TABLE 1. Cellular and biochemical analysis of SF from RA and OA patients.

\begin{tabular}{l|ccc}
\hline & RA (mean \pm SEM, values range $)$ & OA (mean \pm SEM, values range $)$ & $P \leq$ \\
\hline Leukocytes $10^{3} / \mathrm{mL}$ & $10.5 \pm 2.1(1.5-21)$ & $1.95 \pm 0.7(0.2-4.8)$ & $\cdot 01$ \\
Neutrophiles $\%$ & $81.1 \pm 2.7(65-93)$ & $26.7 \pm 3.3(16-39)$ & $\cdot 001$ \\
Neutrophiles $10^{3} / \mathrm{mL}$ & $8.7 \pm 1.8(1.2-18.3)$ & $0.4 \pm 0.1(0.06-0.77)$ & $\cdot 001$ \\
Lymphocytes $\%$ & $15.9 \pm 2.3(7-32)$ & $70.2 \pm 3.9(58-84)$ & $\cdot 001$ \\
Lymphocytes $10^{3} / \mathrm{mL}$ & $15.9 \pm 2.3(7-32)$ & $1.5 \pm 0.6(0.1-4)$ & $\mathrm{NS}$ \\
Monocytes $\%$ & $2.91 \pm 0.9(0-9)$ & $1.7 \pm 0.6(0-4)$ & $\mathrm{NS}$ \\
\hline Total protein $\mathrm{g} \%$ & $4.9 \pm 1.2(4.4-5.8)$ & $4.5 \pm 1.5(4.1-5.2)$ & $\mathrm{NS}$ \\
Albumines $\mathrm{g} \%$ & $2.1 \pm 1.5(1.4-2.9)$ & $1.5 \pm 1.4(1.1-2.0)$ & $\mathrm{NS}$ \\
Lactoferrin $\mu \mathrm{g} / \mathrm{mL}$ & $3.8 \pm 0.2(3.2-5.2)$ & $2.8 \pm 0.2(2-3.5)$ & $\cdot 01$ \\
\hline
\end{tabular}

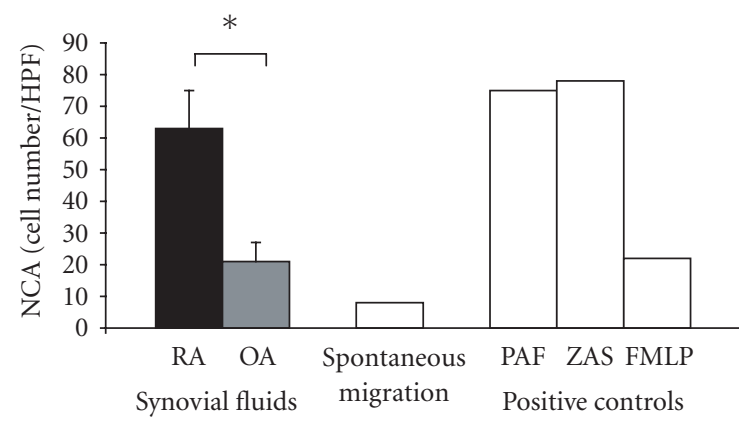

(a)

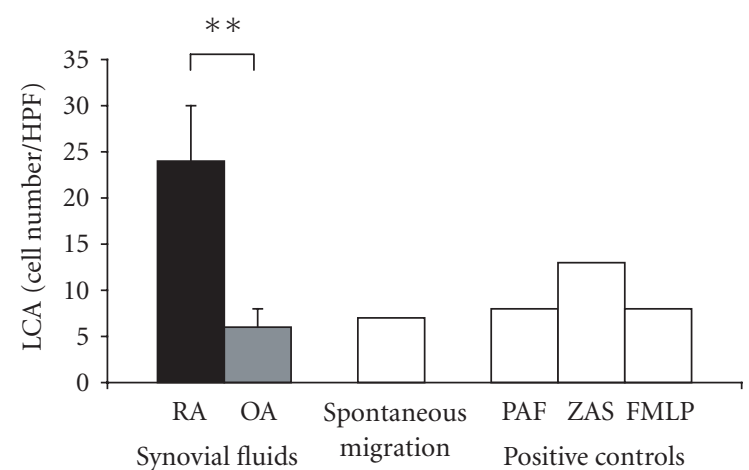

(b)

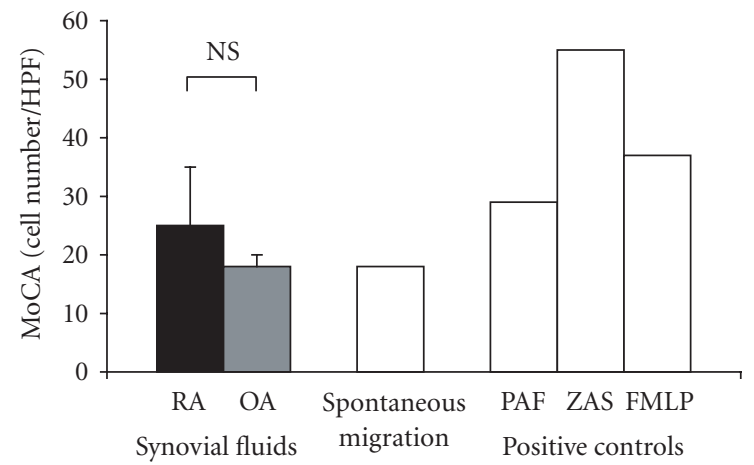

(c)

FIGURE 1. (a) Synovial fluids from patients with RA reveal high chemotactic activity for neutrophils (NCA). Rheumatoid SFs show remarkably stronger NCA as compared to OA SF; mean values \pm SEM are presented, $* P \leq .05$. (b) Synovial fluids from patients with RA show high chemotactic activity for lymphocytes (LCA). SFs from patients with OA do not induce chemotaxis of lymphocytes; mean values \pm SEM are presented, ${ }^{* *} P \leq .01$. (c) Synovial fluids from patients with RA show slight chemotactic activity for monocytes (MoCA) while synovial fluids from patients with OA do reveal MoCA. No difference in MoCA between RA and OA SF has been detected; mean values \pm SEM are presented; NS: not significant.

$47 \pm 7 \%$ of ZAS chemotactic activity. In SF from OA patients, LCA and MoCA were at the level of spontaneous migration.

\section{RANTES in SF}

RANTES concentration was determined in 11 RA and 5 OA SFs. The presence of high RANTES levels was observed in all rheumatoid SF $(145 \pm 36 ; 30-390 \mathrm{pg} / \mathrm{mL})$. Small amount of RANTES was detected only in 2 of 5 osteoarthritic SF $(2 \pm 1 ; 0-5 \mathrm{pg} / \mathrm{mL})$. RANTES concentration in SF supernatants correlated positively with the chemotactic activity for the whole population of mononuclear cells, expressed as the sum of LCA and MoCA $(R=0.61, P<.05)$ and to a weaker degree with 


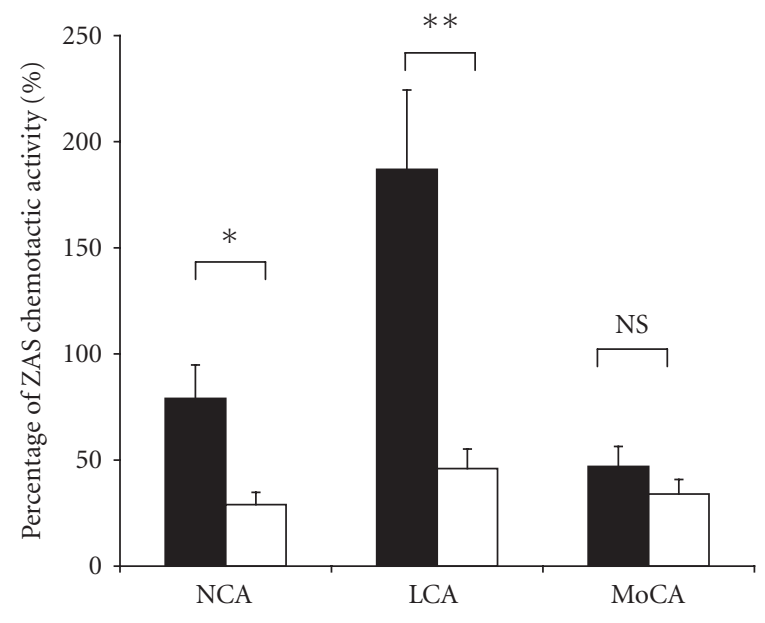

FIgURe 2. Chemotactic activity for neutrophiles (NCA), lymphocytes (LCA), and monocytes (MoCA) expressed as percentage of ZAS chemotactic potential in SF from patients with RA (closed bars) and OA (open bars); ${ }^{*} P<.05,{ }^{* *} P<.01$; NS: not significant.

LCA $(R=0.52, P<.05)$. A surprising finding was a positive correlation of RANTES with percentage and absolute number of neutrophils $(R=0.77, P<.001)$ and a negative correlation with percentage of lymphocytes $(R=$ $-0.74, P<0.01)$. Correlations between RANTES and albumin $(R=0.57 ; P<0.05)$ and LF $(R=0.58 ; P<0.05)$ were also found.

\section{Discussion}

We have demonstrated that synovial fluids from RA patients express strong chemotactic activity towards peripheral blood leukocytes. Neutrophils were the strongest population attracted by the SF, which is in line with previous reports $[7,8]$. Although SF derived from patients with $\mathrm{OA}$ also demonstrated chemotactic activity for neutrophils, its potency was threefold lower than that in rheumatoid SF. The chemotactic activity for neutrophils revealed a positive correlation with the neutrophils percentage in SF, demonstrating that chemotactic molecules present in SF might be responsible for the neutrophils recruitment into the articular cavity.

Synovial fluids from RA patients were also characterised by high chemotactic activity for blood mononuclear cells, which appeared to be higher for lymphocytes than that for monocytes. However, rheumatoid SF induced chemotaxis of lymphocytes with the potency several times weaker than for neutrophiles. The chemotactic activity for lymphocytes in rheumatoid SF have also been reported by other authors [9, 10]. Matsubara observed a relatively low chemotactic activity for monocytes in rheumatoid synovial fluids, which was confirmed by our results [7]. In our study, SF from OA patients had no influence on chemotactic migration of mononuclear cells, as opposed to other studies, in which a chemotactic activity for monocytes was noticed [11]. Cellular and biochemical characteristics of SF studied are typical of RA and OA. High neutrophiles number and high LF concentration observed in RA SF together with correlation of LF with number and percentage of neutrophils confirm that $\mathrm{LF}$ is a protein secreted by activated neutrophils $[12,13]$.

Increasing amount of data from in vitro experiments as well as from clinical studies identify RANTES as an important mediator in RA [3]. We found high concentration of RANTES in rheumatoid SF, which was at comparable level to previous studies $[14,15]$. However, contrary to the other authors we found only trace amounts of RANTES in SF from OA patients. A marked positive correlation between SF RANTES and chemotactic activity for MNC is in agreement with study of Ellingsen et al who showed also the correlation between RANTES SF level and clinical signs of RA [16]. Such a strong correlation suggests that RANTES may be responsible to a significant extent for high chemotactic activity for MNC. In our study we also noted positive correlation of RANTES in SF with the chemotactic activity for lymphocytes (however, this correlation was lower than that for MNC) which is in line with a cellular target for RANTES as a chemoattractant $[17,18]$. The role of RANTES as one of the crucial chemotactic factors for lymphocytes in RA was depicted in the study showing that neutralisation of RANTES in rheumatoid synovium culture supernatants reduces the chemotactic activity of these supernatants for T cells [19]. Moreover, it was shown that RANTES besides a chemotactic potential had the ability to modulate the in vitro production of IL-6 and IL-8 in fibroblastic-like synoviocytes culture model [20].

Volin observed the correlation between RANTES and the number of leukocytes in SF [14]. However role of RANTES in joints pathology and the relation between RANTES and recruitment of particular cell types to SF have not been analysed. In the view of the positive correlation between RANTES and chemotactic activity for MNC and lymphocytes in SF it was surprising to find a negative correlation between RANTES and the percentage of lymphocytes and a strong positive correlation with number of neutrophils. In the basis of this finding one might assume that RANTES in SF is also a chemoattractant for neutrophils. There are some data supporting such a hypothesis. In the transgenic mice model with increased RANTES expression, a considerable influx of neutrophils into lungs was observed [21]. It has been also shown that IFN- $\gamma$ treated neutrophils migrate towards RANTES [22].

The negative correlation between SF RANTES and lymphocytes number may suggest that RANTES promotes migration of mononuclear cells (including lymphocytes) from vessels and synovial fluid to the synovium. This speculation is supported by the recent study showing that rheumatoid synovial fibroblasts produce considerable amount of RANTES [23]. In this context the high SF RANTES concentration and the positive correlation between this chemokine and SF neutrophils may be regarded as a reflection of the intensity of inflammation in the synovium. 
It is also of high importance to mention that besides RANTES many other chemokines and lipid mediators with chemotactic potential have been shown to be abundantly expressed in RA SF. IL-8 and other members of CXC family like ENA-78 or GRO $\alpha$ have been identified as important chemoattractants for neutrophils in RA joints $[24,25,26]$. These mediators may contribute to the high NCA in RA SF studied. However it has been difficult to demonstrate for IL-8 the correlation between its level and neutrophils number [27]. When discussing the factors determining the NCA in inflammatory SF it is also of importance to consider the contribution of leukotriene B4 that is a potent chemoattractant and activator of granulocytes, and it has been detected in large amounts in RA SF [28, 29]. As far as chemotactic activity for mononuclear cells is concerned besides RANTES, other CC chemokines should be considered, like for example MIP- $1 \alpha$, a chemoattractant for lymphocytes, and monocytes that has been shown to be abundant in RA SF [30].

Development of the inflammatory infiltrate in synovial fluid and synovium compartment is a crucial event in the pathomechanism of inflammatory arthritis. Antirheumatic drugs such as metotrexat and leflunomid have a counteracting effect on this mechanism by inhibiting both in vitro and in vivo migration of peripheral blood neutrophils [31]. Determination of the role of RANTES and other chemokines in the regulation of leukocyte influx to the affected joints may enable working out new pharmacotherapy methods. Such therapies would be directed to well characterised cell populations and could have potential therapeutic effect at the early stages of the disease.

\section{ABBREVIATIONS}

\begin{tabular}{ll}
\hline Acronym & Term \\
\hline ELISA & enzyme linked immunosorbent assay \\
ENA-78 & epithelial neutrophil-activating peptide 78 \\
FMLP & formyl methionyl leucyl phenylalanine \\
GRO $\alpha$ & growth-regulated oncogene $\alpha$ \\
HPF & high power field \\
IFN- $\gamma$ & interferon $\gamma$ \\
IL & interleukin \\
LCA & chemotactic activity for lymphocytes \\
LF & lactoferrin \\
MIP-1 $\alpha$ & macrophage inflammatory protein-1 $\alpha$ \\
MNC & mononuclear cells \\
MoCA & chemotactic activity for monocytes \\
NCA & chemotactic activity for neutrophils \\
OA & osteoarthritis \\
PAF & platelet-activating-factor \\
poly-HRP & polymer of horseradish peroxidase \\
RA & rheumatoid arthritis \\
RANTES & regulated upon activation, normal T cell \\
SF & expressed and secreted \\
ZAS & synovial fluids \\
\hline
\end{tabular}

\section{ACKNOWLEDGMENT}

The study was supported by the Medical University of Lodz, Grant no 503-131-1.

\section{REFERENCES}

[1] Zvaifler NJ, Boyle D, Firestein GS. Early synovitissynoviocytes and mononuclear cells. Semin Arthritis Rheum. 1994;23(6 suppl 2):11-6.

[2] Elford PR, Cooper PH. Induction of neutrophilmediated cartilage degradation by interleukin- 8 . Arthritis Rheum. 1991;34(3):325-332.

[3] Boiardi L, Macchioni P, Meliconi R, Pulsatelli L, Facchini A, Salvarani C. Relationship between serum RANTES levels and radiological progression in rheumatoid arthritis patients treated with methotrexate. Clin Exp Rheumatol. 1999;17(4):419425.

[4] Katschke KJ Jr, Rottman JB, Ruth JH, et al. Differential expression of chemokine receptors on peripheral blood, synovial fluid, and synovial tissue monocytes/macrophages in rheumatoid arthritis. Arthritis Rheum. 2001;44(5):1022-1032.

[5] Qin S, Rottman JB, Myers P, et al. The chemokine receptors CXCR3 and CCR5 mark subsets of T cells associated with certain inflammatory reactions. J Clin Invest. 1998;101(4):746-754.

[6] Arnett FC, Edworthy SM, Bloch DA, et al. The American Rheumatism Association 1987 revised criteria for the classification of rheumatoid arthritis. Arthritis Rheum. 1988;31(3):315-324.

[7] Matsubara S, Yamamoto T, Tsuruta T, Takagi K, Kambara T. Complement C4-derived monocytedirected chemotaxis-inhibitory factor. A molecular mechanism to cause polymorphonuclear leukocytepredominant infiltration in rheumatoid arthritis synovial cavities. Am J Pathol. 1991;138(5):12791291.

[8] Stojan B, Borel JF, Loewi G. Chemotactic effect of joint effusions. Ann Rheum Dis. 1974;33(5):425-427.

[9] al-Mughales J, Blyth TH, Hunter JA, Wilkinson PC. The chemoattractant activity of rheumatoid synovial fluid for human lymphocytes is due to multiple cytokines. Clin Exp Immunol. 1996;106(2):230-236.

[10] Miossec P, Dinarello CA, Ziff M. Interleukin-1 lymphocyte chemotactic activity in rheumatoid arthritis synovial fluid. Arthritis Rheum. 1986;29(4):461-470.

[11] Koch AE, Kunkel SL, Shah MR, et al. Macrophage inflammatory protein-1 beta: a C-C chemokine in osteoarthritis. Clin Immunol Immunopathol. 1995;77(3):307-314.

[12] Afeltra A, Caccavo D, Ferri GM, et al. Expression of lactoferrin on human granulocytes: analysis with polyclonal and monoclonal antibodies. Clin Exp Immunol. 1997;109(2):279-285.

[13] Esaguy N, Aguas AP, Vilanova M, Silva MT. Activation of human neutrophils by phorbol ester 
decreases the cytoplasm compactness and the lactoferrin content of the granulocytes. J Leukoc Biol. 1991;50(5):444-452.

[14] Volin MV, Shah MR, Tokuhira M, Haines GK, Woods JM, Koch AE. RANTES expression and contribution to monocyte chemotaxis in arthritis. Clin Immunol Immunopathol. 1998;89(1):44-53.

[15] Suzuki N, Nakajima A, Yoshino S, Matsushima K, Yagita H, Okumura K. Selective accumulation of CCR5+ T lymphocytes into inflamed joints of rheumatoid arthritis. Int Immunol. 1999;11(4):553559.

[16] Ellingsen T, Buus A, Moller BK, Stengaard-Pedersen $K$. In vitro migration of mononuclear cells towards synovial fluid and plasma from rheumatoid arthritis patients correlates to RANTES synovial fluid levels and to clinical pain parameters. Scand J Rheumatol. 2000;29(4):216-221.

[17] Schall TJ, Bacon K, Toy KJ, Goeddel DV. Selective attraction of monocytes and T lymphocytes of the memory phenotype by cytokine RANTES. Nature. 1990;347(6294):669-671.

[18] Utsunomiya I, Tani K, Gong W, Oppenheim JJ, Wang JM. Differential expression of binding sites for chemokine RANTES on human T lymphocytes. Eur J Immunol. 1997;27(6):1406-1412.

[19] Shadidi KR, Thompson KM, Henriksen JE, Natvig JB, Aarvak T. Association of antigen specificity and migratory capacity of memory T cells in rheumatoid arthritis. Scand J Immunol. 2002;55(3):274-283.

[20] Nanki T, Nagasaka K, Hayashida K, Saita Y, Miyasaka N. Chemokines regulate IL- 6 and IL- 8 production by fibroblast-like synoviocytes from patients with rheumatoid arthritis. J Immunol. 2001;167(9):53815385.

[21] Pan ZZ, Parkyn L, Ray A, Ray P. Inducible lungspecific expression of RANTES: preferential recruitment of neutrophils. Am J Physiol Lung Cell Mol Physiol. 2000;279(4):L658-666.

[22] Bonecchi R, Polentarutti N, Luini W, et al. Upregulation of CCR1 and CCR3 and induction of chemotaxis to CC chemokines by IFN-gamma in human neutrophils. J Immunol. 1999;162(1):474479.

[23] Pierer M, Rethage J, Seibl R, et al. Chemokine secretion of rheumatoid arthritis synovial fibroblasts stimulated by Toll-like receptor 2 ligands. J Immunol. 2004;172(2):1256-1265.

[24] Deleuran B, Lemche P, Kristensen M, et al. Localisation of interleukin 8 in the synovial membrane, cartilage-pannus junction and chondrocytes in rheumatoid arthritis. Scand J Rheumatol. 1994;23(1):2-7.

[25] Koch AE, Kunkel SL, Harlow LA, et al. Epithelial neutrophil activating peptide-78: a novel chemotactic cytokine for neutrophils in arthritis. J Clin Invest. 1994;94(3):1012-1018.
[26] Koch AE, Kunkel SL, Shah MR, et al. Growthrelated gene product alpha. A chemotactic cytokine for neutrophils in rheumatoid arthritis. J Immunol. 1995;155(7):3660-3666.

[27] Koch AE. Links Chemokines and their receptors in rheumatoid arthritis: future targets? Arthritis Rheum. 2005;52(3):710-721.

[28] Gaudreault E, Stankova J, Rola-Pleszczynski M. Involvement of leukotriene B4 receptor 1 signaling in platelet-activating factor-mediated neutrophil degranulation and chemotaxis. Prostaglandins Other Lipid Mediat. 2005;75(1-4):25-34.

[29] Davidson EM, Rae SA, Smith MJ. Leukotriene B4, a mediator of inflammation present in synovial fluid in rheumatoid arthritis. Ann Rheum Dis. 1983;42(6):677-679.

[30] Koch AE, Kunkel SL, Harlow LA, et al. Macrophage inflammatory protein-1 alpha. A novel chemotactic cytokine for macrophages in rheumatoid arthritis. $J$ Clin Invest. 1994;93(3):921-928.

[31] Kraan MC, de Koster BM, Elferink JG, Post WJ, Breedveld FC, Tak PP. Inhibition of neutrophil migration soon after initiation of treatment with leflunomide or methotrexate in patients with rheumatoid arthritis: findings in a prospective, randomized, double-blind clinical trial in fifteen patients. Arthritis Rheum. 2000;43(7):1488-1495. 


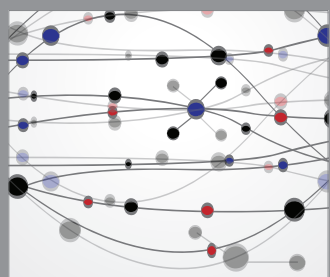

The Scientific World Journal
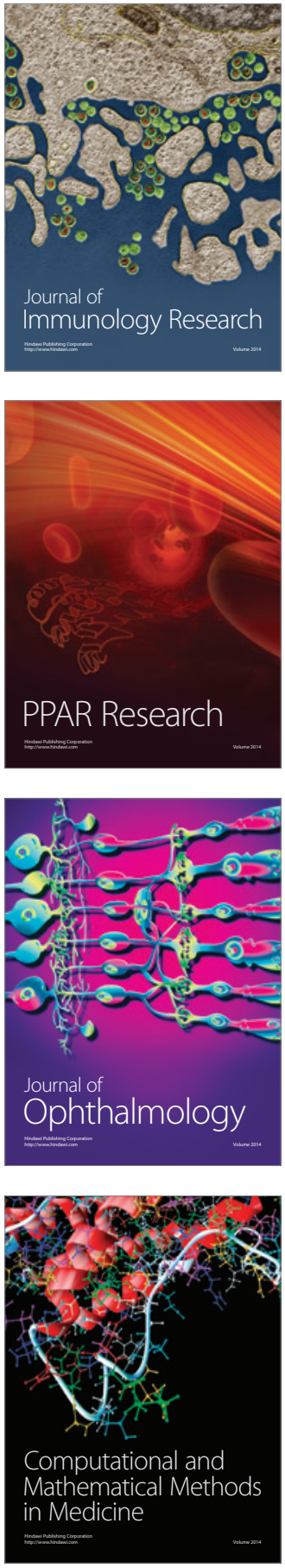

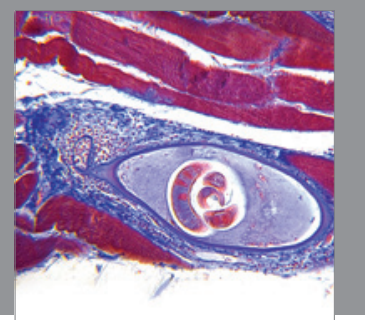

Gastroenterology

Research and Practice
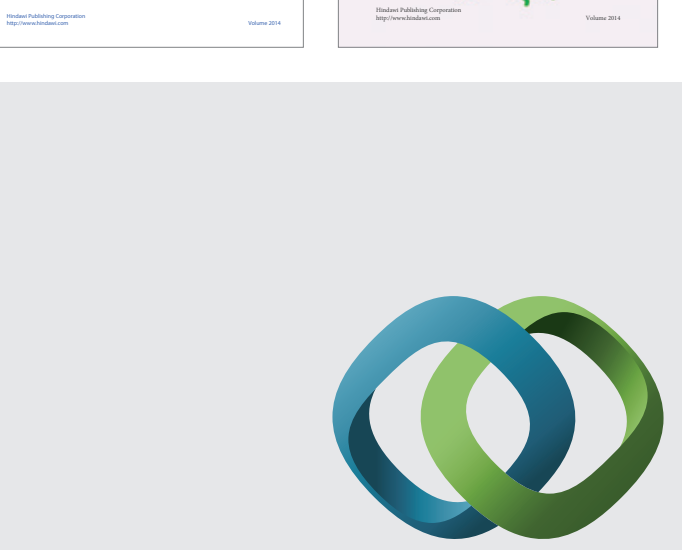

\section{Hindawi}

Submit your manuscripts at

http://www.hindawi.com
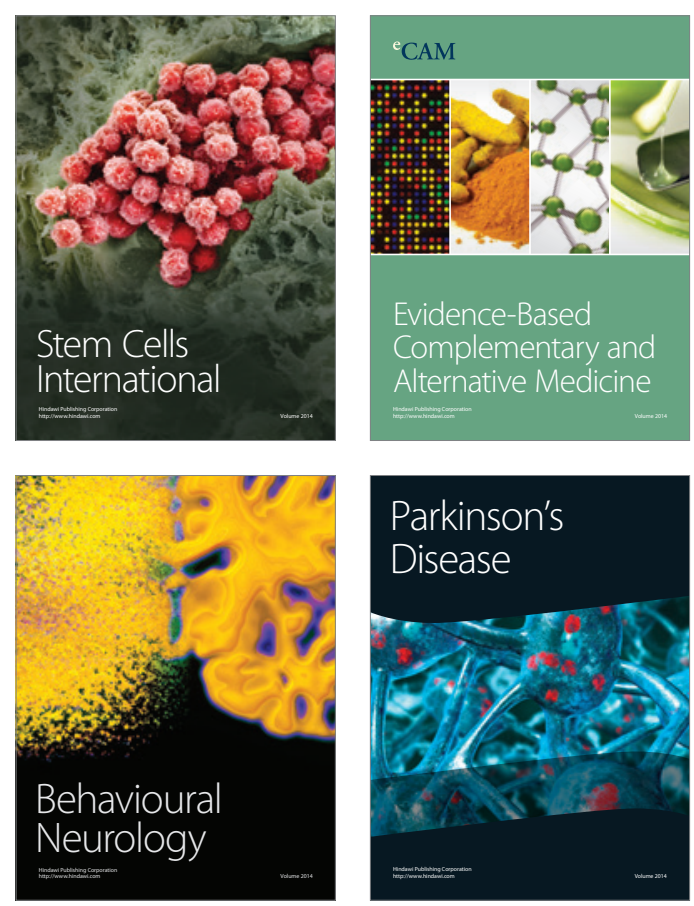

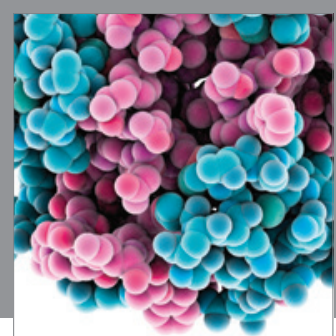

Journal of
Diabetes Research

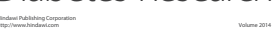

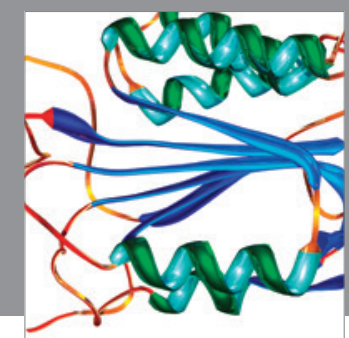

Disease Markers
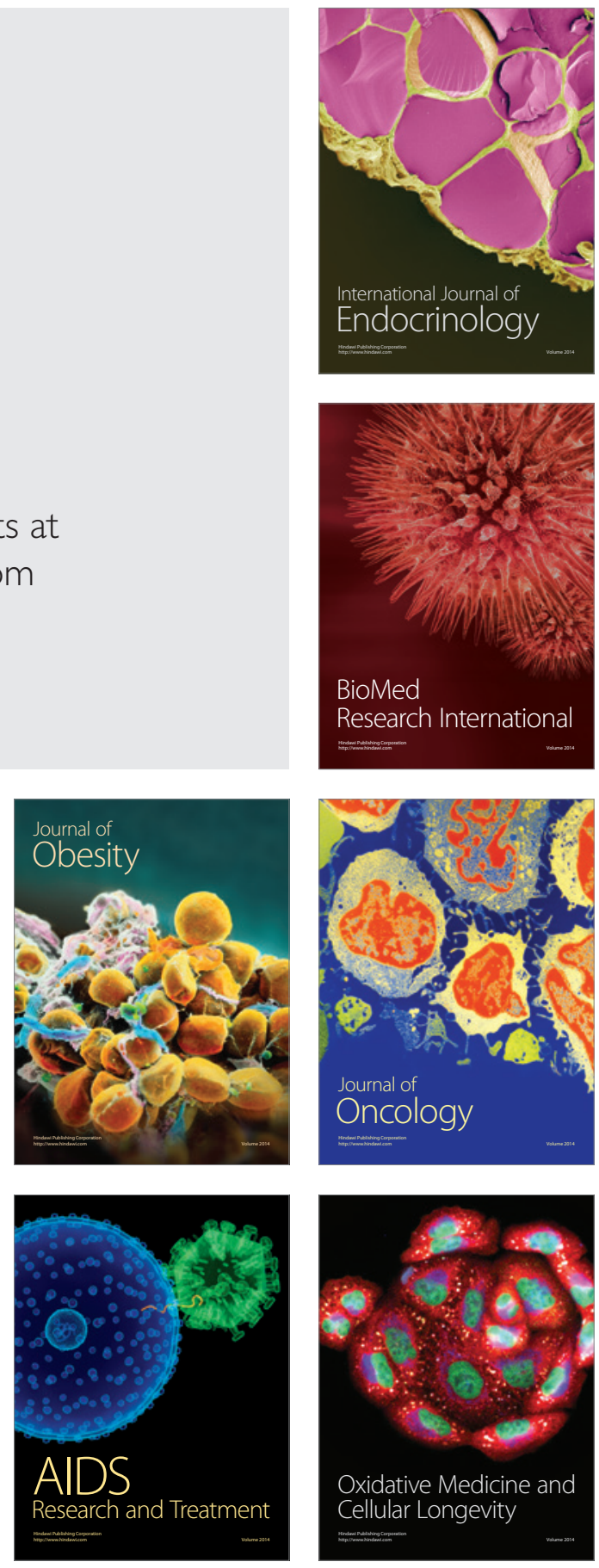